\title{
Da posse indirecta no Codigo Civil (1) (2)
}

\author{
Gondim Neto \\ (Professor da Faculdade de Direito de Recife)
}

Nenhum instituto juridico tem merecido maior attenção dos escriptores do que a posse.

As velhas controversias, aqui e ali, surgem, sempre renovadas e eternamente insoluveis, em perpetuo desafio á inteligencia e á cultura dos homens de direito.

Isso, quer tomemos por base a fragmentaria e irregular fonte romana, quer encaremos a posse na sua evolução posterior, atravez do direito canonico e medieval, até os codigos da actualidade.

Só uma coisa perdura incontestavel: a discrepancia das leis e das idéas.

Não pretendemos fazer resurgir neste pequeno trabalho, feito longe de nossa bibliotheca, com os limitados recursos de notas e de alguns livros, indispensaveis companheiros de viagem, um estudo decisivo para a solução de tão magnos problemas, mas apenas uma ligeira critica da divisão dia posse em directa e indirecta, no Codigo Civil Brasileiro, seguindo, aliás, as pegadas de legislações que o antecederam.

Não tenho, devo dizer, de logo, nenhuma admiração pelo trabalho scientifico de nosso Codificador, em materia de posse, onde, restringindo-nos ao nosso thema, e, deixando de parte, assim, outras grosseiras incongruencias, só desco-

(1) Conferência realizada, na Faculdade de Direito de S. Paulo, em 12 de maio de 1938.

(2) Este trabalho foi revisto pelo autor. 
brimos a incompleta trasladação de doutrinas corporificadas no Codigo Allemão.

Pelo art. 486 do Codigo Civil Brasileiro "quando, por força de obrigação, ou direito, em casos como o do usufructuario, do locatario, se exerce temporariamente, a posse directa, não annulla esta ás pessoas, de quem elles a houveram, a posse indirecta"

Outra cousa não fez o legislador que reproduzir o art. 868 do Codigo tedesco: "Besitzt Jemand eine Sache als Niessbraucher, Pfandgläubiger, Pächter, Miether, Verwahrer oder in einem ähnlichen, Verhältnisse, vermöge dessen er einem Anderem gegenüber auf Zeit zum Besitze berechtigt oder verplichtet ist, so ist auch der Andere Besitzer (mittelbarer Besitz)"

A posse indirecta do art. 486, que é a mesma Mittelbarer Besitz do Codigo tedesco, corresponde á possessio ad usucapionem, sem detenção, isto é, a posse do proprietario que cedia a cousa a outrem.

"A especie de posse indirecta se caracteriza pela circumstancia de ser reconhecida uma posse sem o poder de facto; que o possuidor directo não quer exercer o poder possessorio em nome proprio, mas, como intermediario do outro, recebendo essa vontade firmeza e efficacia juridica com a relação de dependencia autorizada entre as partes interessadas, em virtude da qual o possuidor directo é somente obrigado ou autorizado temporariamente á posse em relação ao possuidor indirecto; e que, para solução dessa relação reciproca, a lei estabeleceu uma posse dupla - o possuidor directo e o indirecto conservam a cousa ao mesmo tempo em uma posse indivisa" (Endemann, Lehrbuch des Bürgerlichen Rechts, vol. II, § 32).

Essa doutrina da bipartição da posse indirecta e directa não me parece logica, nem scientifica.

Ella se funda num velho erro dos romanos, de que a sciencia juridica, ainda hoje, se não poude libertar inteiramente, na antiga confusão da propriedade com o seu objecto. 
Como é sabido, o dominio sujeita o bem sobre que recae, ao seu titular, em geral e na totalidade de suas relações, salvo as limitações impostas pela lei.

E' o chamado caracter abstracto da propriedade, que embora despojada de quasi todo o seu conteúdo, pela constituição dos jura in re aliena, reduzida mesmo á simples nuda proprietas, inteiramente paralysada, conserva, todavia, seu conceito totalitario.

Ainda pelo mesmo motivo, e sob o ponto de vista puramente processual, não necessita o proprietario, na acção negatoria, fazer a prova da ausencia de servidões, facto que decorre naturalmente de seu direito, antes, é á parte contraria que incumbe demonstrar o direito limitativo na cousa alheia.

Outra consequencia de ordem juridica material, revelase, por sua vez, na força attractiva do dominio, comprehendendo, ipso jure, novamente em seu conteúdo todas as faculdades dos jura in re, anteriormente destacadas como direitos autonomos, e pois extinctos.

Com sua clareza habitual, explica historicamente o pandectista H. Dernburg, "a capacidade e a tendencia do dominio a uma comprehensão total do bem"

"No antigo direito romano sómente se conhecia o direito de propriedade com completo direito de dominação. Isso fica demonstrado por uma vista sobre o desenvolvimento historico dos direitos reaes na cousa alheia. Superficie e direito vectigal (emphyteuse) evidentemente, só alcançaram a natureza real na época do processo formulado. Tambem o direito de penhor só recebeu protecção por intermedio do Pretor. No tempo da vigencia exclusiva do Jus Civile, dos direitos reaes na coisa alheia unicamente as servidões eram conhecidas. Entre essas, só as servitudes praediorum rusticorum, e, na verdade, as de caminho e de agua eram consideradas res mancipi, pois as servitudes praediorum urbanorum e as servidões pessoaes, especialmente o usofructo, eram tidas como res nec mancipi. Isto é um indicio de que as ultimas são de data mais recente. Vê-se tambem do edicto pretoriano sobre o dever de prestar caução do 
usof ructuario, que este se não desenvolvia sem o auxilio do Pretor. Á época mais antiga só pertencem as servidões de transito e agua. No periodo primitivo nem mesmo essas deviam existir. E' duvidoso si eram conhecidas na época das doze taboas, pois não são citadas nos fragmentos conservados dessa lei. Servidões de transito, no mais antigo tempo, eram dispensaveis, pois na attribuição das propriedades territoriaes geralmente se attendia aos meios de communicação. As relações de agua veem já satisfatoriamente reguladas nas doze tabuas, pela actio aquae pluviae arcendae.

Quando no correr do tempo, em virtude de necessidades inadiaveis, os direitos reaes em cousa alheia foram apparecendo, conservou a propriedade, por abstracção juridica, o caracter hypothetico, que lhe era inherente no posterior Direito Romano" (Pandekten, 6. ${ }^{a}$ ed. $\S 192$ ).

D'ahi a expressão res mea est, como indicativa da existencia do direito de propriedade sobre determinada cousa, visto como o dominio conceitualmente abrange todo seu objecto.

Mas os romanos, apezar de seu genio juridico, não possuiam, a este respeito, as claras noções que temos hoje, e d'ahi, a falsa concepção sobre o caracter dos elementos patrimoniaes, facto que tanta influencia teve sobre a noção da posse, mesmo no presente.

Distinguindo as cousas em corporales e incorporales, elles oppunham apparentemente as cousas aos direitos, quando, na realidade, consideravam, pela confusão do dominio com o seu objecto, a propriedade como o unico bem corporeo e todos os outros direitos como incorporeos.

Si porém attendermos ao direito em si, vemos logo que todos são incorporeos, inclusive a propriedade que, afinal, na substancia, nada mais é que o complexo das faculdades que isoladamente constituem os jura in re aliena, não podendo, assim, ter natureza diversa delles.

Por outro lado, se attendermos ao objecto, todos os direitos reaes são corporeos, porquanto recaem sobre um substracto material. 
Convem notar que essa incongruente noção de res corporales e incorporales não se confunde com a classificação actual dos objectos de direito em materiaes e immateriaes, comprehendidos entre estes as creações literaria, artistica e scientifica.

A confusão do dominio com seu objecto, revelada na classificação dos componentes do patrimonio, determinou igualmente essa falsa noção da posse e, em vez de se falar em possessio dominii seul proprietatis, surgiu uma possessio rei.

Isso impediu a extensão natural do instituto aos outros direitos, que evidentemente não se confundiam com o seu objecto, sendo apenas como anomalia admittida a juris quasi possessio.

As necessidades praticas foram sendo satisfeitas pela concessão da rei possessio nos casos da chamada posse derivada, e da juris possessio das servitutes praediorum vel personarum.

Ainda assim, mesmo sem serem confundidas com o objecto, como acontecia com o dominio, foi sem duvida o caracter de direito real das servidões que levou os romanos a admittirem a quasi posse a seu respeito, o que não occorreu com outros direitos a que faltava o substracto material, sendo puramente obrigacionaes, como a locação.

A cousa que, por um lado, pela sua falsa identificação com a propriedade, separava esse direito dos jura in re aliena, por outro, pela materialidade do objecto do direito, os approximava.

Não se conseguiu então a noção integral da posse, mas surgiu a juris possessio anomala e restricta.

0 art. 486 de nosso Codigo, bem como o 868 do Codigo Allemão, não determinam taxativamente os casos de posse directa, limitando-se ambos a alguns exemplos, que podem ser estendidos a casos analogos. 
D'ahi a applicação da noção não só em materia de direitos reaes obrigacionaes, como ainda em direitos de familia e das successões.

Como o direito real de conteudo amplissimo, merece especial attenção o caso do emphyteuta.

Pelo nosso Codigo será elle um possuidor exclusivo, de dirèito, ou simplesmente o possuidor directo?

A questão já debatida entre os juristas allemães relativamente aos casos do Erbbaurecht e Erbpachtrecht que substituiram, respectivamente, a Superficies a a Emphyteusis dos romanos, encontra identicas, sinão maiores difficuldades em nosso Direito.

Tratando da materia, affirma KNIEP: - "Não ha duvida, todavia de que o superficiario (Erbbauberechtigten) deve ser considerado como possuidor da cousa. Aquelle que concede a Superficies (Erbbaurecht) alcança, desde logo, posse indirecta, si estabeleceu uma condição extinctiva ou a concessão se deu por um prazo determinado. Mas, tambem onde foi convencionado o direito de superficie de duração illimitada, sempre devem restar ao concedente alguns direitos de posse (Besitzesbefugnisse) de modo que nós não lhe podemos contestar a posse indirecta" (Der Besitz des Bürgerlichen Gesetzbuches, pag. 135).

Essa opinião está longe, entretanto, de ser geralmente acceita, como bem vemos das palavras transcriptas do commentario de Blanck: " $E$ ' discutido si superficie (Erbbaurecht) e emphyteuse (Erbpachtrecht) produzem posse indirecta. A verdade é que esses direitos podem ser constituidos por tempo illimitado e, assim, se não pode dizer que ao superficiario e ao emphyteuta, possuidores do immovel gravado, seja attribuida a posse temporaria. A corrente dominante devia, portanto, logicamente, negar a posse indirecta. Na concepção aqui adoptada, o factor tempo nāo é inteiramente decisivo" (Plancks Kommentar zum Büergerlichen Gesetzbuch, 4. ${ }^{a}$ ed., vol. II, pag. 84).

Convem não esquecer que pélo direito allemão a superficie (Erbbaurecht) pode ser sujeita não só á condição como 
a termo extinctivo, não sendo, assim, necessariamente perpetuo, como occorre entre nós ex vi do disposto no art. 679 .

Effectivamente, não parece razoavel applicar ao emphy. teuta que, pelo nosso Codigo, necessariamente, tem "dominio util" perpetuo, os principios do art. 486 sobre posse directa e indirecta, visto como lhe falta o requisito da temporariedade.

A menos que se pense na possibilidade do commisso, que, entretanto, não tira ao direito o caracter de perpetuidade.

Em trabalho especial sobre o nosso thema, Der Mittelbare Besitz des Bürgerlichen Gesetzbuches, publicado in Archiv für die civilistiche Praxis, o Prof. Wendt depois de chamar a attenção para a limitação contida nas palavras "auf Zeit" do Cod. tedesco, as quaes correspondem rigorosamente ao adverbio "temporariamente" empregado pelo nosso legislador, diz de modo incisivo: "Isto concerne especialmente ao superficiario e ao emphyteuta, por serem ambos autorisados in perpetuum. O proprietario, por consequencia, não terá, junto a elles, direito á posse mediata" (Vol. 87, pag. 61).

Julgou-se, certamente, que os remedios petitorios, no seu caso, são sufficientes para a defeza de seus interesses o que não occorre com as relações temporarias, em que o possuidor indirecto aguarda, com a devolução do bem, o restabelecimento de sua posse exclusiva, sendo, assim, summamente interessado em manter inalterada a situação.

Mas, como resolver quanto ao usucapião já começado, si não lhe reconhecemos a posse indirecta?

Os romanos, em cujos textos memoraveis e impereciveis vamos encontrar todas as raizes do direito moderno, tambem scindiam, em certos casos, a relação possessoria.

Assim, coexistiam as posses do credor e do devedor pignoraticio. 
Jávolenus attribue a este a possessio ad usucapionem e áquelle possessio ad reliquas omnes causas (L. 16 de usurp.).

No mesmo sentido se manifesta Julianus quanto ao devedor pignoraticio, L I \& 15 e no L. 36 de poss. respetivamente, videri eum possidere, intellegitur possidere.

Facto identico occorria com o precario dans e o preca. rio acipiens, continuando o primeiro o usucapião começado e cabendo ao segundo os restantes direitos da posse, e igualmente em todos os casos que Savigny chamou de "posse derivada"

Não esqueçamos tambem a pretendida existencia de uma posse injusta ao lado de uma posse justa, doutrina que tanto abalo trouxe ao principio preconizado por Celsus de que duorum quidem in solidum dominium vel possessionem esse non posse (L. $3 \S 5$ de poss.).

Entende Renda que "essa regra não soffre excepção quando alguem alcança a posse de uma cousa de má fé ou de modo injusto ou illegal, porquanto o facto da posse indipende desses elementos que não lhe attingem a substancia L. $3 \S 5$ da posse: Nam in summa possessionis non multum interest, juste quis an injuste possideat. Sempre é possuidor apenas aquelle que tem o poder de facto sobre a cousa, com a correspondente vontade, e isso não soffre alteração com o facto de poder o anterior possuidor readquirir a posse perdida, por meio judicial, seja mediante acções possessorias ou petitorias" (A. Renda, Der Besitz nach Oesterreichischen Recht, 4." ed. pag. 491).

Essa doutrina da simultaneidade das duas posses, justa e injusta, vem sustentada nos textos (L. $3 \S 5 \mathrm{D}$. de posses. 41, 2; L. $15 \S 4 .^{\circ}$ de prec. 43, 26; Savigny, $\S 11$ ).

Ella contrariava a natureza da posse e implicava na corruptela de sua noção, tendo sido regeitada pela maioria dos juristas romanos e do mesmo modo pelo direito Justinianio (L. 3 \& 5 D. de posses.; L. 19 pr. de prec.; L 5 § 15 commod. 13,6).

Foi certamente essa ficção da permanencia da posse do possuidor injustamente despojado e não a duplicidade dos 
interdictos que determinou entre os romanistas a doutrina do effeito recuperatorio do interdictum Uti possidetis, transformando-se essa injustificavel ficção numa formula theorica que evitava, na pratica, a necessidade de um processo duplo, bastando a allegação da exceptio vitiosae possessionis, quando o usurpador intentasse o referido interdictum retinendae.

Essa doutrina culminou com a admissão por alguns escriptores, do Uti possidetis como interdictum recuperandae possessionis, usado directamente pelo ex possuidor contra o usurpador, o que representa uma verdadeira inversão das normas de processo e das ideas sobre posse.

$O$ effeito recuperatorio, mesmo entendido limitadamente, isto é, como a recuperação da posse perdida pela invocação da exceptio vitiosae, vem, a nosso vêr, contrariar a propria natureza das acções duplices entre as quaes se incluem os interdictos possessorios, pela evidente differença de situações juridicas e pedidos das partes, uma invocando a posse actual e outra pretendendo apenas restaurar uma posse que reconhece perdida.

Isso não impedia, porém, que o possuidor injustamente desapossado, accionado com o Uti possidetis pelo usurpador turbado, pudesse reconvir com o interdicto Unde Vi, obtendo dest'arte a restauração de sua posse anterior.

Modernamente essa questão da possibilidade de uma possessio plurimum in solidum tem sido de novo debatida entre os escriptores.

Pensa Sokolowski que, si attendermos ao facto de vir sendo a posse e sua protecção livremente reguladas pelo direito positivo, são admissiveis varias especies de posse sobre a mesma cousa.

Cita os casos, já discutidos por nós, da coexistencia das posses do proprietario ou precario dans e do devedor pignoraticio com as do precario accipiens e do credor pignoraticio, bem como a pretendida concurrencia da posse justa com a posse injusta admitidda pelos juristas romanos.

Attribue a mudança de ideas a esse respeito a uma variação de concepção metaphysica. 
Sómente as posteriores investigações theoricas sobre a posse, a philosophica construcção da immediata relação do sujeito á noção da cousa e a seu substracto physico, teriam determinado a regra alludida.

Conclue que "esse principio construido pela metaphysica rigorosamente logica dos antigos não é obrigatorio para nós, tanto mais quanto a moderna theoria da posse partiu da protecção possessoria e do emprego desta, conhecendo tão pouco uma noção aprioristica da posse, quanto o mais antigo direito romano" (Der Besitz in klassischen Recht und dem deutschen bürgerlichen Gesetz).

A idéa da simultaneidade de varias posses é tambem acceita por Krückmann e Giercke.

Entretanto, a regra formulada por Celsus é tão logica e verdadeira quanto o principio da identidade.

Ao jurista cabe conceber theoricamente as diversas noções scientificas, condemnando as defeituosas formas adoptadas inconsideradamente pelo legislador, antes que reputal-as como a crystalização definitiva do direito e da doutrina.

O direito prussiano, segundo nos informa MeIscheider (Besitz und Besitzschutz, pags. 123-124) conhecia a posse perfeita correspondendo a possessio romana com animus domini; a posse imperfeita, abrangendo a posse do credor pignoraticio e a posse daquelles que, detendo a cousa em virtude de direito real ou pessoal, reconhecem o direito superior; finalmente a simples detenção.

Todos esses possuidores e até os detentores gozam de protecção possessoria em face de terceiros.

Entre elles, porém, a protecção possessoria é limitada, só a obtendo o detentor quando investido de um direito de retenção.

Quanto aos possuidores perfeito e imperfeito, não poderão resolver pelo possessorio suas questões de direito.

Assim, não pode o locatario defender-se com o possessorio contra os actos a que o locador se julga contractualmente autorizado e, por seu lado, não pode o locador im- 
pedir com as acções possessorias os excessos do locatario ao direito que lhe foi concedido.

Em todo o caso vê-se no direito prussiano uma verdadeira divisão dos effeitos da posse, sendo estendida a protecção judicial até aos detentores, facto que colloca o Landrecht prussiano como o mais caracterizado precusor do codigo civil allemão e do brasileiro.

A idea de que o possuidor material de uma cousa pudesse proporcionar a posse a um outro já se encontra expressa no direito romano, sob a autoridade de Paulus (Pignori rem acceptam pro alieno possidemus, L. 13 pr. de usurp. 41,3) de Julianus (Qui pignoris causa fundum creditori tradit, intelligitur possidere, L. 36 de poss. 41,2) e de Celsus (L. 18 eod.).

Uma differença substancial, entretanto, apresentam os codigos do Brasil e da Allemanha, em relação ao direito romano, pois, emquanto elles concedem concomitantemente a protecção possessoria aos possuidores directo e indirecto, o direito romano conferia ao ultimo o unico effeito de continuar o usocapião, attribuindo ao primeiro os demais effeitos da posse, em particular, a protecção pelos interdictos.

Em certos casos mesmo a detenção da cousa se alliava á quasi posse do direito, como occorria com o usufructuario, considerado, hoje, naquelles codigos, possuidor directo.

Em synthese, podemos affirmar com Regelsberg (Der gerichtliche Besitzschutz, etc. pag. 9): “Uma dupla proteção de posse de cousa como o codigo civil allemão $\S 869$ reconhece não era admittida no direito romano. Ao detentor protegido, os romanos concediam a posse, dizendo-se de não protegido que elle praestat alienae possessioni ministerium"

Os romanos, a principio, materializavam muito a relação possessoria, dando um caracter demasiadamente physico ao corpus. 
Só com o evolver do direito a posse se foi, por assim dizer, espiritualizando, elevando-se de pura relação de facto a verdadeira relação juridica.

Tambem os romanistas se acostumaram a encarar a posse predominantemente pelo seu aspecto corporeo, pelo seu lado objectivo.

Viam nella antes o poder de facto, ou sua possibilidade, sobre a cousa material, que o exercicio de um direito mais ou menos amplo.

Esse vicio tambem occorreu com Savigny que, depois de reconhecer sabiamente que a posse consiste no exercicio do direito, propriedade ou jus in re aliena, acrescenta, com infelicidade, que "como na verdadeira posse a cousa é possuida (possessio corporis), e não a propriedade, assim tambem não se devia falar em posse das servidões (possessio juris). Mas, como não temos outra palavra... nada nos resta senão usarmos essa expressão impropria" (Recht des Besitzses, 7. ${ }^{\text {a }}$ ed. pag. 192).

A unidade da noção da posse, no grande chefe da escola historica, se realiza pela negativa da posse da propriedade, considerada méra possessio rei, á qual elle tambem reduz toda a posse de direitos na cousa alheia.

Identica concepção materialista encontramos no pandectista Windscheid, por quanto tambem elle encara a posse de direito como uma limitada posse de cousa (Lehrbuch des Pandektenrechts, $\S \S 151$ e 163).

E' o velho erro dos romanos de que ainda os novos se não puderam libertar inteiramente, embora aqui e alli, algumas vezes, transpareça a verdadeira noção da posse, o que ocorre, por exemplo, com Ihering quando considera a posse como o exercicio da propriedade subordinando-a, porém, ao falso criterio da normalidade do uso e da utilização economica do bem.

A esse respeito, nosso Codigo Civil, como seu precursor allemão, apenas representa a moderna consagração legislativa de uma concepção que se impunha mais pela rotina do que pela segurança de principios e exactidão de idéas. 
A coexistencia de duas posses - a directa e a indirecta - é uma dupla monstruosidade scientifica e legal que somente difficuldades praticas pode acarretar.

As differenças substanciaes que apresentam, alliadas á possibilidade de coexistencia de posses indirectas de diversos gráus, isto é, essa verdadeira superposição de possuidores, bem revela uma hierarchia de direitos, cujo exercicio se opera e deve ser respeitado como posse, nos limites e na amplitude reconhecida e assegurada pela ordem juridica.

Em vez de conservar a envelhecida e erronea idéa de posse de cousas, causa principal da não extensão da noção da posse aos direitos pessoaes, na antiguidade, melhor seria que reconhecesse o nosso Codigo uma posse de dominio, isto é, a posse de direito mais ampla que se concebe sobre um bem.

Ao lado della, e com sua noção limitada pela maior ou menor extensão dos direitos por cujo exercicio são constituidas, poderiam apparecer, hierarchicamente subordinadas, as demais posses de direito.

Ao codificador competeria tambem regular a materia quanto aos direitos pessoaes e, em particular, ás relações obrigacionaes, concedendo aos credores e até a devedores, como o depositario, a protecção possessoria, nos casos julgados necessarios, recusando-a quando se lhe afigurasse inconveniente.

Com isso seria evitada a condemnavel bipartição da posse em directa e indirecta, bem como a possibilidade de differentes gráus da ultima, em que os mais afastados possuidores têm posse de cousa apenas por ficção legal.

O civilista austriaco ReNdA já salientava ser a posse "a possibilidade de facto, oriunda de uma acção, do reiterado exercicio de um direito.

Quando esta possibilidade se refere ao exercicio do conteúdo do direito de propriedade temos a posse de propriedade ou de cousa; contrariamente, se a acção traz a possibilidade do exercicio de outro direito que não a propriedade, então se trata de posse de direito" (obra cit. pag. 90). 
Em extenso trabalho publicado no "Archiv für die civilistiche Praxis", vol. 108, KrückManN, depois de passar em revista essas idéas, entende que, apesar da inexactidão na formulação theorica, a doutrina do direito commum no seculo 19 considerava a posse como o exercicio das faculdades do dominio ou dos direitos reaes de conteúdo limitado.

Salienta tambem a tendencia geral para uma conceituação unitaria da posse, orientação que já se encontra esboçada em SAvignx.

Conclúe, finalmente, affirmando que "Actos de posse são, tanto na posse de cousa como na de direito, aquelles pelos quaes se exercem as dependentes (propriedade) ou autonomas (direitos na cousa alheia) faculdades do dominio (pags. 200-201).

"Não existe posse de cousa, toda posse é apenas posse de direito, sendo a posse de cousa limitada ou illimitada posse de direito de propriedade.

Posse não é o estado do exercicio de facto, ao contrario, é a possibilidade juridicamente reconhecida de exercer, de qualquer modo, determinado direito.

Quem tem a possibilidade juridicamente reconhecida de agir sobre a cousa, tem a possibilidade juridicamente reconhecida de exercer a propriedade; quem tem a possibilidade juridicamente reconhecida de exercer um direito, tem a posse sobre este direito" (pags. 186-187).

Sem duvida alguma, não endossamos o pensamento de KRÜCKMANN em todas as suas consequencias, particularmente na certa confusão que faz entre posse e direito a posse.

Todavia, com justiça, não podemos deixar de salientar sua notavel contribuição, pondo em evidencia, de modo incisivo, não só o conceito unitario da posse, mediante a identificação desta com o exercicio dos differentes direitos, distruibuindo inteiramente a velha e erronea noção da posse de cousa, não obstante as criticas, em parte procedentes, que lhe fizeram Stintzing no "Archiv für die civilistische Praxis", vol. 109, e E. FrnzI, "Il possesso dei diritti"

A posse, por conseguinte, é dessas noções que dominam toda a extensão do direito, devendo, assim, ser tratada e 
estudada como um assumpto de ordem geral, e não no direito das cousas.

Não esqueçamos a amplitude que a noção da posse vem alcançando continuamente desde os direitos canonicos e medieval que a estenderam aos direitos pessoaes, até á actualidade.

Ella se applica inquestionavelmente ao proprio estado das pessoas como se verifica, por exemplo, dos artigos 203 e 206, relativos ao estado de casados.

Foi igualmente estendida pelo Codigo aos direitos obrigacionaes, credito ou obrigação (depositario), e a outros casos semelhantes (mesmo em direito da familia e das successões) cujo exercicio proporciona ou acarreta a detenção de cousas materiaes, com a denominação de posse directa, isto é, como posse de cousa.

A posse occorre, ou melhor, diz-se que ha posse toda vez que, sem se ferir a questão da legitimidade, se desfructa uma situação juridica, exerce um direito ou cumpre uma obrigação, com o reconhecimento e a garantia do direito positivo.

A posse independe, assim, da existencia real, mas não conceitual dos direitos e situações juridicas, por cuja realização pratica ou effectividade ella é constituida, ainda que indevidamente e até de modo illegal, como o possuidor de má fé que goza de protecção contra todos, á excepção do esbulhado que lhe pode oppôr o caracter vicioso de sua posse.

Tanto sob o ponto de vista da permanencia de sua situação juridica, como da protecção os possuidores directo e indirecto gozam de autonomia.

Assim, os factos occorridos com o possuidor directo geralmente não affectam o possuidor indirecto, a menos que, não criem obstaculos a posse deste, o mesmo succedendo no sentido inverso. 
A causa é o vinculo que une ambos os possuidores, não podendo assim faltar, pois nella se revela a vontade de ambos e o reconhecimento por elles da posse reciproca.

Não necessita, porém, de ter validade juridica ou existencia objectiva.

A simples mudança de intenção do possuidor directo não extingue a posse indirecta, a menos que se manifeste com actos exteriores que indiquem claramente o esbulho.

Tem inteira applicação aqui a regra nemo sibi ipse causam possessionis mutare potest.

Esse principio que alcança não só as varias especies de possuidores, como até os detentores, se acha adoptado pelo artigo 492 do Codigo Civil quando dispõe que "salvo prova em contrario, entende-se manter a posse o mesmo caracter, com que foi adquirida".

Ambos os possuidores gozam tambem da protecção possessoria.

E' bem verdade que nosso Codigo não regulou especialmente a materia como o fez o Codigo Allemão.

$E^{\prime}$ portanto nas disposições deste ultimo que vamos encontrar os subsidios para o nosso direito.

Pelo direito allemão goza o possuidor directo de todos os meios de defesa da posse em face de terceiros, podendo, assim, usar das acções possessorias, como da legitima defesa.

$O$ possuidor indirecto está tambem protegido mediante as acções de esbulho e de manutenção em face de terceiros.

Em caso de subtracção da posse o possuidor indirecto é autorizado a exigir sua restituição ao directo.

Caso este não possa ou não queira acceital-a, pode o possuidor indirecto exigir que a cousa lhe seja entregue.

Ha ahi uma simplificação de procedimento judicial, pois, sendo elle obrigado pela relação causal, direito real ou pessoal, a entregar a cousa ao possuidor directo, pode obter que o auctor do esbulho mesmo o faça, ficando restabelecida desse modo a situação anterior.

Tambem está autorizado o possuidor indirecto a usar da acção de manutenção. 
Entende Wendt que ambas as acções só são concedidas ao possuidor indirecto sob a condição de que tenha sido practicada violencia contra o possuidor directo.

As presupposições das acções devem existir, assim, na pessoa de um outro só podendo o possuidor accionar quando o possuidor directo mesmo é autorizado á acção.

o ponto de que tudo depende é que o possuidor directo, contra a sua vontade, seja turbado na posse ou della esbulhado.

O que occorrer com o consentimento do possuidor directo só pode ser remediado ou reparado pelo processo petitorio.

Realizadas, porém, as condições das acções, pela violencia ao possuidor directo, fica livre ao indirecto intental-as, sendo indifferente a iniciativa ou inatividade daquelle na defesa de sua posse (Archv. fur die civ. Praxis, vol. 87, pags. 52 e segs.).

Essa opinião, que é a dominante entre os civilistas allemães, não parece satisfactoria.

Geralmente, a violação da posse indirecta coincide com a da directa, mas é bem possivel que isso não aconteça.

Assim, pode a acção indifferente ao possuidor directo, talvez mesmo por elle autorizada, constituir, todavia, evidente violação da posse indirecta.

Taes os casos em que o locatario autoriza um terceiro a derrubar arvores ou retirar pedras, materiaes estes valiosos para construcção, ou assiste negligentemente ás incursões de visinhos, tornando incertos os limites da propriedade alugada.

Em todas essas hypotheses é evidente que o possuidor indirecto tem um interesse autonomo e urgente na conservação da cousa, cabendo-lhe as acções possessorias de curso mais rapido e, assim, mais efficazes.

Quanto á legitima defesa de sua posse e ao desforço incontinente, pode o possuidor directo exercel-os contra todos, inclusive contra o possuidor indirecto.

E' ponto pacifico. 
Goza este tambem de igual direito?

Esse direito, bastante discutido, em certos casos constitue mesmo o unico meio efficaz para impedir graves e irreparaveis damnos, como se observa de um caso real occorrido com o proprio jurista SokoLowski e por elle relatado.

Um dos seus locatarios agricultores permittiu que o visinho derrubasse dois magestosos carvalhos, cujas frondes magnificas sombreavam e impediam a cultura do trigo.

Essas arvores de inestimavel valor, felizmente, não foram sacrificadas, graças á intervenção energica dos vigias que ameaçaram de empregar a propria força para evitar a derrubada (obra citada, pags. 255-256).

Esse facto, apparentemente banal, é, todavia, bastante significativo para o assumpto ventilado.

Uma questão mais importante ainda é a de saber se a ambos os possuidores competem reciprocamente as acções possessorias nos casos de turbação e esbulho commettidos. por um contra o outro.

Como ordinariamente a causa entre ambos os possuidores tem validade juridica, bastam quasi sempre os meios. petitorios para acautelar os interesses lesados.

Isso, entretanto, não impede que o possuidor directo possa defender sua posse judicialmente ou não contra os actos illegaes do indirecto.

Quanto a este, entende Wolf que não goza de protecão possessoria contra aquelle (Lehrbuch des Burgerlichen Rechts, de Enneccerus, Kipp e Wolf, vol. 2. $§ 20$ ).

0 Codigo allemão não resolveu expressamente a hypothese, como o fez com a composse, no art. 866.

Para nós a proteç̧ão deve ser admittida, intervindo a questão da causa, cuja validade não é exigida, apenas para: fixar as qualidades dos possuidores, isto é, a que titulo elles. possuem, distinguindo-os, assim, dos casos de posse injusta e simples detenção.

Em synthese: o art. 486 do Codigo Civil brasileiro é apenas uma formula erronea pela qual praticamente foi. 
admittida a posse da propriedade, dos direitos reaes, de certos direitos pessoaes e do depositario.

0 mesmo resultado poderia ser obtido mais scientificamente se abandonassemos a noção antiquada de posse de cousa, substituindo-a pela posse de direitos, caracterizada pelo seu exercicio.

Aliás, conforme dissemos acima, a possivel superposição de varias posses indirectas, com gráus diversos e cada vez mais remotos, indica antes uma hierarchia de direitos, simultaneamente possuidos que, na verdade, uma pluralidade de posses de cousa, o que só por ficção se pode admittir. 